\title{
Dampak Faktor Eksternal Terhadap Pertumbuhan Ekonomi Indonesia
}

\section{EcceS: \\ Economics Social and Development Studies}

\author{
Rossanto Dwi Handoyo", \\ Angga Erlando' ${ }^{2}$, \\ Ilham Septiyanto ${ }^{3}$ \\ 1,2,3 Universitas Airlangga \\ 1,2,3 Jalan Airlangga No.4, Airlangga, Kecamatan Gubeng, Kota Surabaya, Jawa Timur 60286, \\ Indonesia \\ E-mail: rossanto_dh@feb.unair.ac.id ${ }^{1}$, angga.erlando@feb.unair.ac.id ${ }^{2}$, \\ Ilhamseptiyan56@gmail.com ${ }^{3}$
}

(Article history) Received: 2020-04-12, Revised: 2020-04-27, Accepted: 2020-05-27, Available online: 2020-06-20 DOI: $10.24252 /$ ecc.v7i1.13382

\section{Abstrak: Dampak Faktor Eksternal Terhadap Pertumbuhan Ekonomi Indonesia}

Indonesia adalah salah satu negara yang menggunakan pertumbuhan ekonomi sebagai indikator kinerja ekonomi. Pertumbuhan ekonomi yang tinggi dan berkelanjutan sangat diharapkan oleh pemerintah Indonesia, sebagai salah satu upaya untuk mencapai kemakmuran bagi masyarakat Indonesia. Studi ini mencoba melihat pengaruh impor, pengiriman uang (remiten), foreign direct investment (FDI), dan harga minyak dunia terhadap pertumbuhan ekonomi di Indonesia. Estimasi yang dilakukan dalam penelitian ini adalah Autoregressive Distributed Lag (ARDL) analysis method, dan digunakan untuk melihat efek jangka panjang dan jangka pendek. Hasil estimasi menunjukkan bahwa variabel impor secara signifikan memiliki pengaruh negatif terhadap pertumbuhan ekonomi di Indonesia. Sementara itu, variabel FDI memiliki hubungan positif dan signifikan terhadap pertumbuhan ekonomi di Indonesia. Variabel remitansi memiliki hubungan negatif, tetapi tidak signifikan terhadap pertumbuhan ekonomi di Indonesia dalam jangka pendek, selain itu remitansi juga memiliki pengaruh positif, tetapi tidak signifikan terhadap pertumbuhan ekonomi di Indonesia dalam jangka panjang. Sedangkan dalam jangka pendek variabel harga minyak dunia (world oil price) berpengaruh secara signifikan negatif terhadap pertumbuhan ekonomi Indonesia. Rekomendasi yang diberikan, diantaranya perlunya perbaikan dan pengembangan tata kelola pada sektor migas untuk mengurangi ketergantungan impor migas, mendorong model proyek yang dapat mendorong timbulnya kegiatan ekonomi baru, memuculkan kepastian hukum yang jelas dan terpercaya kepada investor khusunya dari asing, dan perlunya pengelolaan remiten yang berorientasi pada 
pemunculan usaha produktif dengan potofolio manjemen keuangan rumah tangga untuk masa depan.

Kata Kunci: Foreign Direct Investment; Impor; Pertumbuhan Ekonomi; Remitansi ; World Oil Price

\section{Abstract: Impact of External Factors on Indonesia's Economic Growth}

Indonesia is one of the country that uses economic growth as an indicator of economic performance. High and sustainable economic growth are highly expected by the Indonesian government, because of high economic growth and sustainability as one of the efforts to achieve prosperity for the people of Indonesia. This study tries to see the effect of imports, remittances, foreign direct investment, and world oil prices on economic growth in Indonesia. The estimation carried out in this study is an Autoregressive Distributed Lag (ARDL) analysis model, and use to see long-term and short-term effects. The estimation results show that the import variable significantly has a negative influence on economic growth in Indonesia. Meanwhile, the foreign direct investment variable has a positive and significant relationship to economic growth in Indonesia. Remittance variables have a negative, but not significant relationship to economic growth in Indonesia in the short term, besides that remittances also have a positive but not significant effect on economic growth in Indonesia in the long-term. Recommendations: improvement and development of governance in the oil and gas sector to reduce dependence on oil and gas imports, encourage government projects that can encourage the emergence of new economic activities, promote clear and reliable legal certainty to investors especially foreign investors, and remittance management oriented to the emergence of productive businesses with portfolio of household financial management for the future.

Keywords: Foreign Direct Investment; Import; Economic Growth; Remittance; World Oil Price

\section{PENDAHULUAN / INTRODUCTION}

Pertumbuhan ekonomi masih dianggap sebagai indikator utama yang digunakan dalam mengevaluasi kinerja ekonomi suatu negara, tidak mengherankan banyak ahli ekonomi concern pada topik ini (Tong dan Qiu, 2020; Peters, 2020; Meyer dan Shera, 2017; Chenaf dan Rougier, 2008; dan Yanikkaya, 2003). Dalam pemahaman teori klasik, pertumbuhan ekonomi suatu negara yang tinggi berarti negara tersebut memiliki kinerja ekonomi yang baik, dan sebaliknya apabila pertumbuhan suatu negara rendah, bahkan negatif berarti negara tersebut memiliki kinerja ekonomi yang buruk (Azoulay at al., 2020; Boldeanu dan Constantinescu, 2015). Kinerja ekonomi suatu negara yang baik akan menyebabkan fundamental makroekonomi negara tersebut relatif kuat. Sebaliknya, jika kinerja ekonomi suatu negara buruk akan menyebabkan fundamental makro ekonomi negara tersebut lemah (Chirwa dan Odhiambo, 2016). Walau demikian, sebenarnya tidak cukup hanya pertumbuhan yang tinggi dengan kinerja ekonomi yang baik. Kualitas 
pertumbuhan berkelanjutan dan inklusif harus jadi bentuk pemerataan kesejahteraan dan kemakmuran masyarakat Indonesia.

Indonesia sebagai negara berkembang terus berupaya mencapai dan mempertahankan pertumbuhan ekonomi jangka panjang secara berkelanjutan, meskipun skenario tersebut tidaklah selalu berjalan sesuai harapan. Ditambah lagi saat ini telah muncul faktor eksternal seperti sistem globalisasi yang semakin meningkat, dan pada sisi yang lain juga muncul pandangan anti globalisasi. Keadaan yang demikian dapat memicu gejolak global dan ketidakpastiannya, sehingga sangat mungkin negara berkembang menjadi lebih rentan dalam menghadirkan pertumbuhan ekonomi yang progresif. Konteks faktor ekternal yang lain juga masih cukup banyak celahnya untuk dikaji, terutama bagaimana dampaknya terhadap pertumbuhan ekonomi di Indonesia. Misalnya, variabel impor, pendapatan remitansi, Foreign Direct Investment (FDI), harga minya dunia, dan lain lainnya (Handley et.al, 2020; Maswana, 2020; Hendrix, 2019; Azman et al., 2010; Barajas, et al., 2009).

Jika melihat Gambar 1 berikut, terlihat pertumbuhan ekonomi Indonesia masih dibawah rata-rata pertumbuhan ekonomi kawasan ASEAN. Menurut World Bank (2017), faktor yang menyebabkan pertumbuhan ekonomi rendah di kawasan negara ASEAN, salah satunya karena kondisi fiskal global yang tidak pasti. Misalnya harga minyak semakin tinggi memacu perlambatan konsumsi domestik dan pemerintah, gejolak ekonomi geopolitik, dan sejenisnya.

Gambar 1. Rata-Rata Per Tahun Pertumbuhan Ekonomi Kawasan ASEAN Periode 2010-2017 (dalam persen)

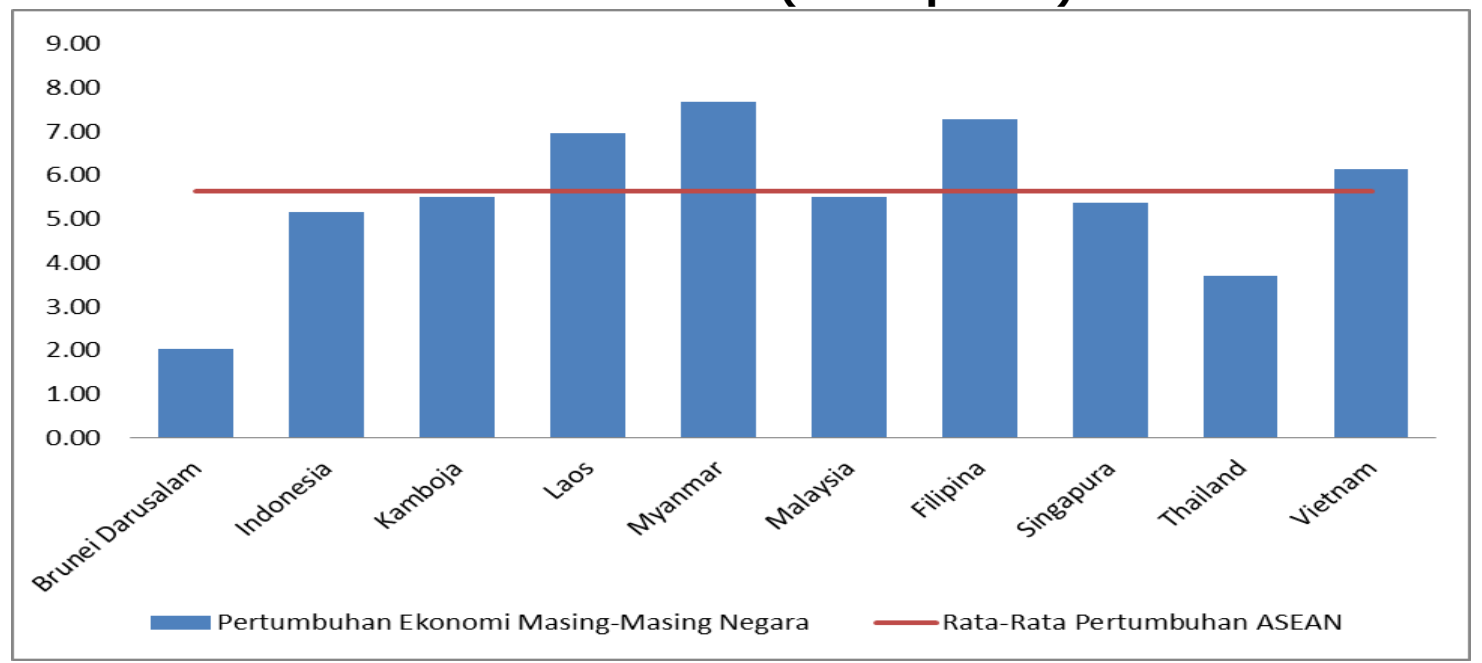

Sumber: World Bank, 2017. 
Sementara itu, pada gambar 2 berikut, menunjukkan sepanjang periode tahun 20122017, realisasi pertumbuhan ekonomi Indonesia tidak mampu mencapai sesuai target. Melesetnya target tahun 2012 disebabkan gejolak ekonomi global, yang mempengaruhi menurunnya optimalisasi dan realisasi belanja pemerintah, terutama belanja modal. Sedangkan tahun 2015 lebih dikarenakan konsumsi rumah tangga dan pertumbuhan belanja modal yang mengalami perlambatan.

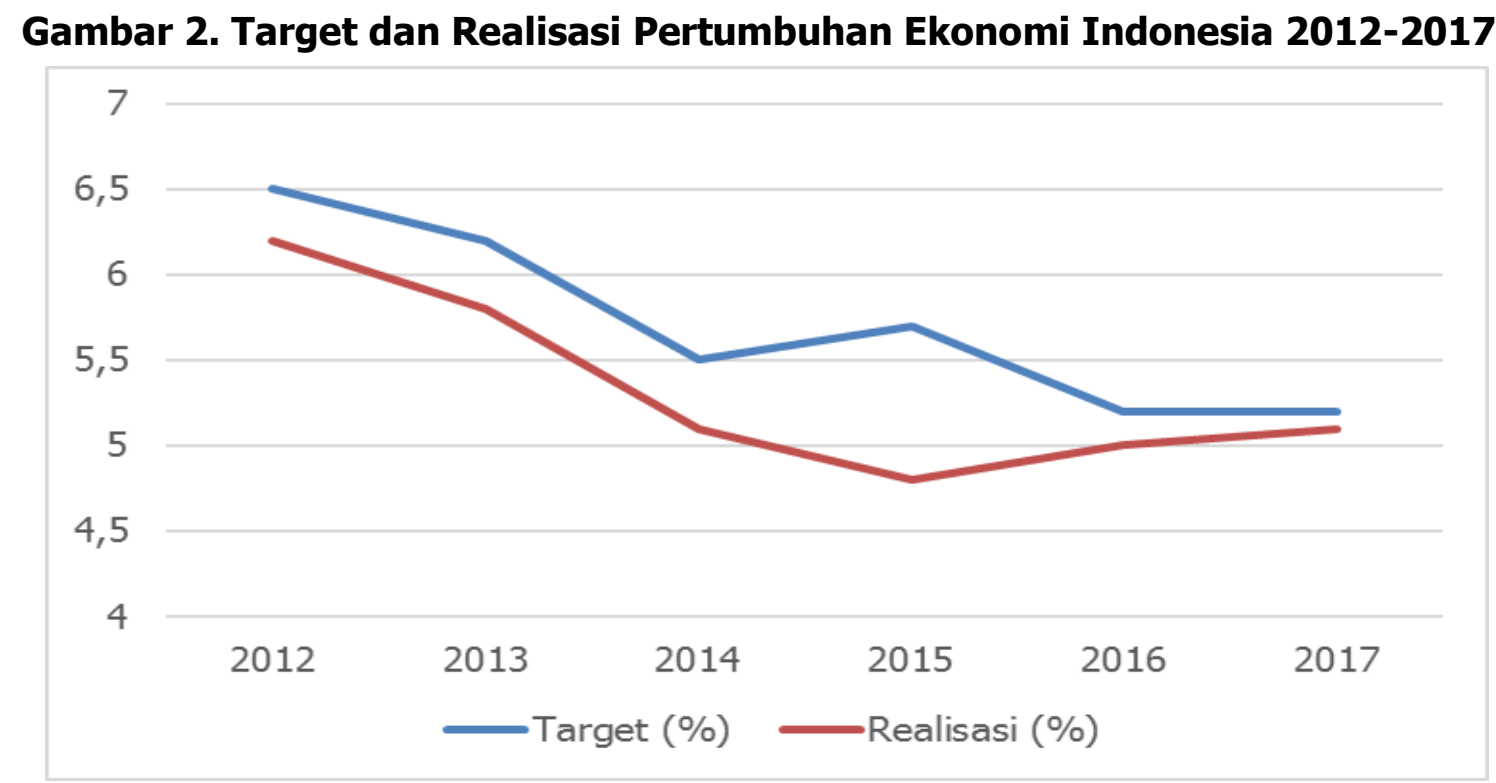

Sumber: Kementerian Keuangan, 2012-2017.

Penelitian ini mencoba mengidentifikasi berbagai macam faktor yang mempengaruhi pertumbuhan ekonomi dari sisi eksternal. Identifikasi faktor yang mempengaruhi pertumbuhan ekonomi pada suatu negara secara empiris perlu didasarkan pada teori, sebagai dasar menganalisis hubungan antar variabel (Chirwa dan Odhiambo, 2016). Faktor eksternal pertama yang diidentifikasi memiliki determinan terhadap pertumbukan ekonomi Indonesia adala aktivitas impor. Ekspansi impor dapat memberi ruang gerak bagi produsen asing guna menguasai pasar domestik dan menguras devisa negara yang relatif sangat dibutuhkan, untuk kepentingan stabilitas moneter dan ekonomi (Adams, 2009). Ekspansi impor juga dapat mengakibatkan produksi dalam negeri kurang kompetitif, sehingga menyebabkan penurunan tingkat produktivitas yang lebih mengarah pada pelemahan pertumbuhan ekonomi. Ekspansi impor mendorong alokasi sumber daya yang kurang optimal dan efisien serta tidak ada stimulasi peningkatan teknologi sehingga menghambat pertumbuhan ekonomi. Pada sisi lain, impor juga dianggap menjadi faktor yang dapat menurunkan pertumbuhan ekonomi (Tremblay, 1990; Esfahani, 1991; Zahongo, 2016). 
Gambar 3 menunjukkan perkembangan impor barang dan jasa Indonesia selama periode 2010-2017, dengan tren yang cukup baik tahun 2010-2014. Impor di Indonesia utamanya dilakukan untuk pemenuhan kebutuhan primer seperti bahan bakar minyak/gas. Sedangkan komoditas selain minyak dan gas (non migas) banyak didominasi barang elektronik dan raw materials. Tren impor sempat berubah, karena tahun 2017 mengalami peningkatan yang dipicu oleh naiknya nilai impor minyak dan gas. Impor barang konsumsi juga mengalami peningkatan. Hal ini karena terdapat beberapa komoditas yang belum bisa dipenuhi dari produksi. Selain itu juga menyusul larangan impor beberapa produk untuk masuk ke Indonesia, sehingga kebutuhan pangan akan mengalami peningkatan. Pada kasus negara berkembang hal tersebut dapat memacu inflasi (Makun, 2017).

Gambar 3. Impor Barang dan Jasa Negara Indonesia Tahun 2010-2017 (dalam triliyun rupiah)

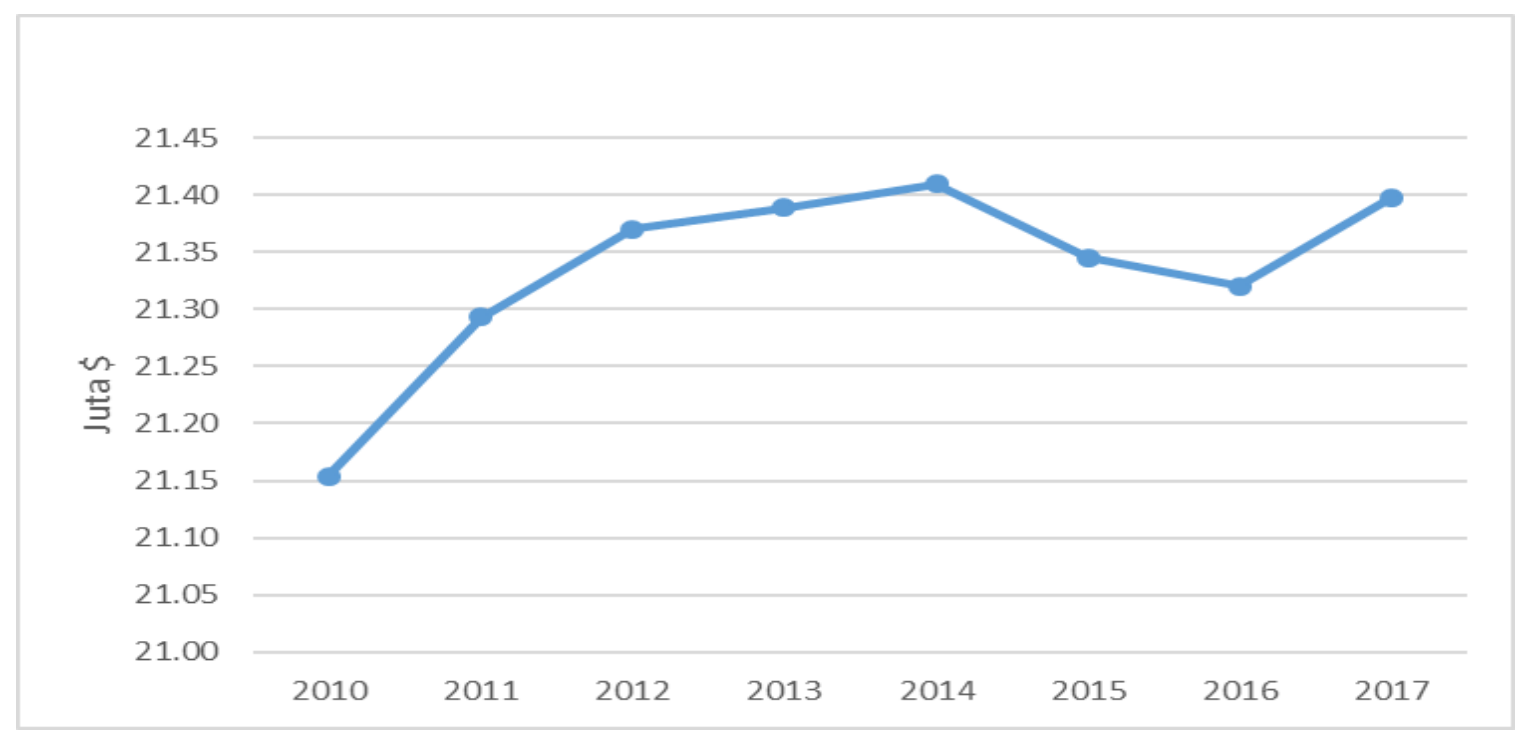

Sumber: World Bank, 2017

Faktor eksternal kedua yang dipertimbangkan berdampak pada pertumbuhan ekonomi Indonesia yaitu remitansi. Ada berbagai perspektif yang saling bertentangan mengenai dampak remitansi terhadap pertumbuhan ekonomi (Sutradhar, 2020). Golongan yang optimis berpendapat bahwa remitansi berdampak positif terhadap pertumbuhan ekonomi. Remitansi yang dihasilkan oleh para migran berpotensi meningkatkan pendapatan negara dan meningkatkan pembangunan sektor keuangan, sehingga mendorong pertumbuhan ekonomi. Remitansi juga dapat meningkatkan pertumbuhan ekonomi karena semakin banyak uang yang dikirimkan ke anggota keluarga di negara asal, akan meningkat 
pendapatan dalam anggota keluarga tersebut. Pendapatan ini dapat digunakan untuk biaya pendidikan maupun membuat usaha kecil serta dapat meningkatkan kesejahteraan anggota keluargannya, sehingga membantu untuk mengurangi kemiskinan (Makun, 2017). Sementara itu, golongan pesimis berpendapat bahwa remitansi berpengaruh negatif terhadap pertumbuhan ekonomi (Tabit \& Moussir (2016). Remitansi di negara berkembang cenderung meningkatkan konsumsi keluarga untuk belanja barang impor, sehingga inflasi mengalami peningkatan dan dapat mendistorsi pertumbuhan ekonomi (Belmimoun et al., 2014).

\section{Gambar 4. Remitansi Indonesia Periode 2010-2017 (dalam milyar US)}

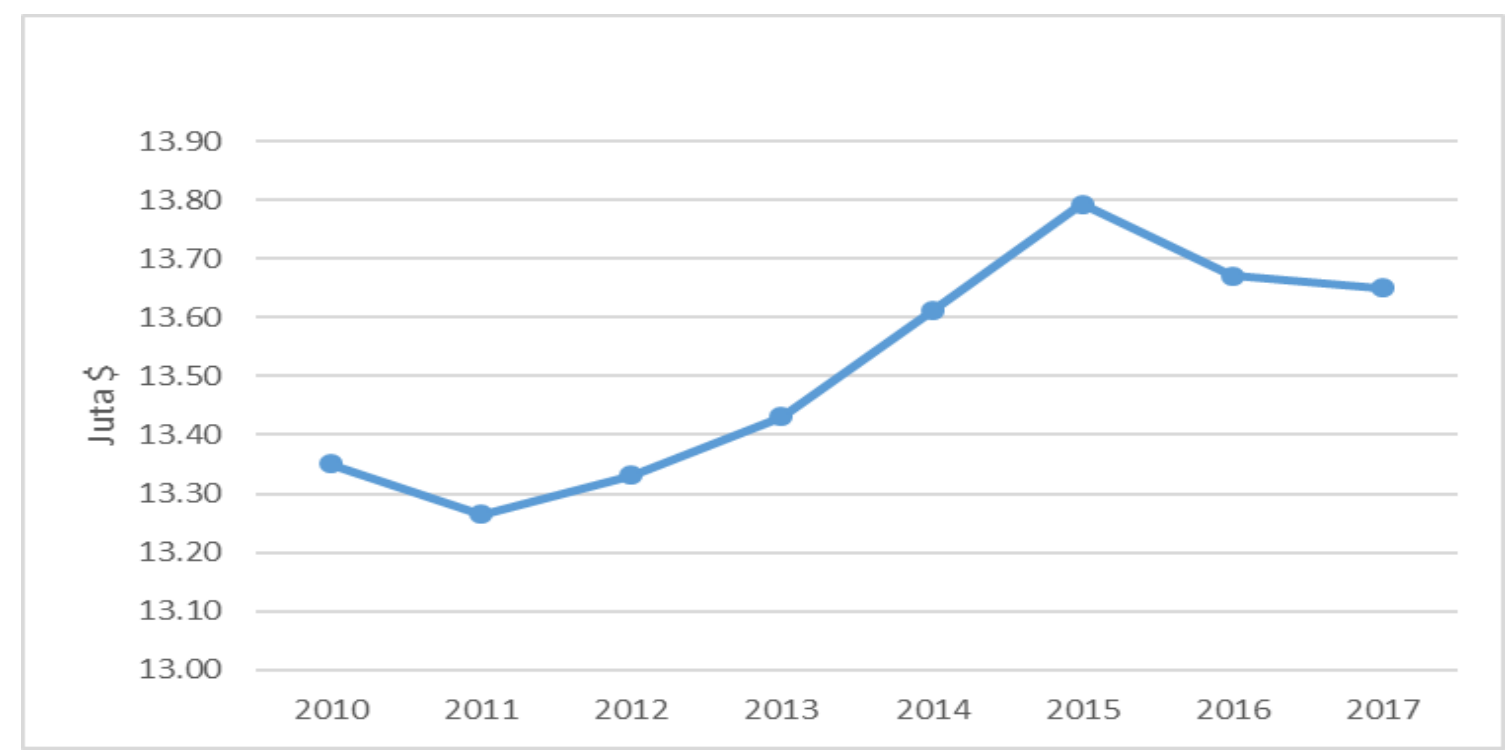

Sumber: World Bank, 2017.

Selama periode 2010-2015 remitansi Indonesia mengalami peningkatan. Hal ini menandakan bahwa secara agregat pendapatan pekerja Indoensia di luar negeri mengalami peningkatan. Hal yang menarik bahwa tahun 2016, nilai remitansi mengalami penurunan karena kebijakan pemerintah yang mendorong peningkatan penempatan pekerja migran Indonesia formal. Selain itu hal ini menjadi dampak nyata dari kebijakan penutupan penempatan TKI informal (moratorium) ke kawasan Timur Tengah, maupun faktor terbatasnya peluang kerja bagi tenaga kerja asing di beberapa negara karena keadaan ekonomi global yang fluktuatif.

Faktor eksternal ketiga yaitu investasi asing langsung (FDI), sebagai sumber pendorong pertumbuhan ekonomi. Dornbusch (2001) berpendapat bahwa investasi adalah permintaan barang dan jasa untuk menciptakan atau menambah kapasitas produksi atau pendapatan di masa mendatang agar dapat menciptakan pertumbuhan ekonomi. Todaro 
dan Smith (2006:137-138), menganggap investasi memiliki peran penting dalam menggerakkan perekonomian suatu negara, karena pembentukan modal memperbesar kapasitas produksi sehingga dapat mendorong pertumbuhan ekonomi. Gambar 4 berikut ini, menunjukkan bahwa FDI inflow di Indonesia bergerak fluktuatif, khususnya periode 20152017.

Gambar 5. FDI Inflow di Indonesia Tahun 2010-2017 (dalam juta US\$)

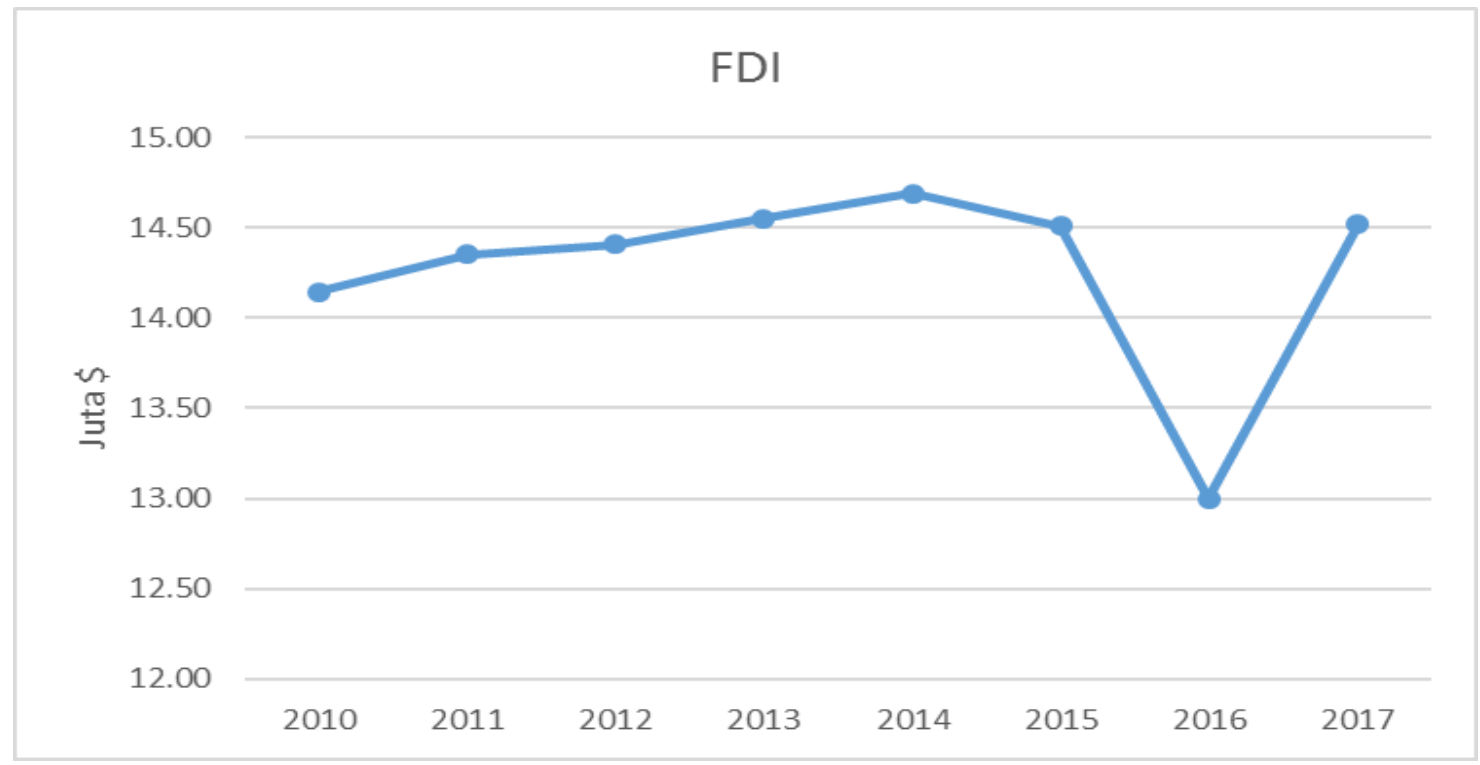

Sumber: World Bank, 2017.

Faktor yang menyebabkan fluktuasi nilai FDI tidak terlepas dari adanya regulasi yang sering berubah di tingkat kementerian terhadap pola kebijakan sektor ketenagalistrikan dan migas, inkonsistensi penerapan UU Minerba No.4 Tahun 2009, sehingga sering dikhawatrikan memacu pelemahan pertumbuhan ekonomi Indonesia. Sementara itu, tahun 2017, FDI inflow mengalami peningkatan yang memberikan harapan dan optimisme untuk mencapai target realisasi investasi periode selanjutnya. Faktor yang menyebabkan peningkatan tersebut yaitu penerbitan dua peraturan baru berupa Peraturan Badan Koordinasi Penanaman Modal Nomor 13 Tahun 2017 tentang Pedoman dan Tata Cara Perizinan dan Fasilitas Penanaman Modal, dan Peraturan Badan Koordinasi Penanaman Modal Nomor 14 Tahun 2017 tentang Pedoman dan Tata Cara Pengendalian Pelaksanaan Penanaman Modal. Faktor lainnya juga tidak terlepas dari peringkat kemudahan berusaha Indonesia yang naik. 
Faktor eksternal keempat yang juga dipetimbangkan dalam menentukan pertumbuhan ekonomi Indonesia yaitu harga minyak dunia. Adanya dampak ekonomi dari shock harga minyak dalam aktivitas ekonomi memiliki efek yang berbeda-beda pada setiap negara. Hal ini dapat terjadi karena adanya perbedaan nilai tukar dan implementasi kebijakan yang diterapkan oleh suatu negara. Bagi perekonomian Indonesia, kebijakan intervensi pemerintah dapat menetralkan perubahan harga. Hal ini dapat mempengaruhi harga minyak dan barang-barang dalam mempercepat proses pertumbuhan ekonomi. Kenaikan harga minyak menyebabkan penurunan output karena kenaikan harga memberikan sinyal berkurangnya ketersediaan input dasar untuk produksi. Akibatnya, laju pertumbuhan ekonomi menurun (Nizar, 2012).

Sebelumnya, memang telah ada penelitian mengenai dampak faktor eksternal seperti oleh Makun (2017). Penelitiannya menguji dan menganalisis pengaruh investasi, impor, dan remitansi terhadap pertumbuhan ekonomi selama periode 1980-2015 di Republic of the Fiji Islands. Metode yang digunakan yaitu ARDL. Kesimpulan penelitian Makun (2018) yaitu investasi, impor, dan remitansi berpengaruh signifikan terhadap pertumbuhan ekonomi di Republic of the Fiji Islands. Selanjutnya, Nizar (2012) juga melakukan penelitan mengenai dampak ekternal harga minyak dunia terhadap pertumbuhan ekonomi. Metode yang digunakan yaitu VAR. Kesimpulan dari penelitian tersebut yaitu fluktuasi harga minyak dunia berpengaruh signifikan terhadap pertumbuhan ekonomi.

Research gap dari penelitian ini dibandingkan dengan beberapa penelitian sebelumnya seperti Makun (2017) serta Nizar (2012) yaitu penggunaan kombinasi dari kedua variabel penelitian diatas, yaitu investasi, impor, remitansi, dan harga minyak dunia sebagai variabel independennya dalam menentukan apakah faktor-faktor tersebut dapat mempengaruhi pertumbuhan ekonomi Indonesia. Penelitian ini bertujuan untuk menganalisis pengaruh faktor eksternal (impor, remitansi, FDI, dan harga minyak dunia) terhadap pertumbuhan ekonomi dalam jangka pendek dan jangka panjang terkait perilaku pelaku ekonomi dalam merespon fenomena shock dalam jangka pendek menuju keseimbangan jangka panjang. Diharapkan penelitian ini memberi kontribusi akademik dari model yang dikembangkan tersebut.

\section{TINJAUAN TEORITIK / LITERATURE REVIEW}

Harrord-Domar dalam Mankiw (2009) sebagai bentuk pengembangan pemikiran Keynes mengenai daya ekonomi dalam persepektif nasional dan tenaga kerja di dalamnya 
Teorinya mengungkap analisis dan kriteria pertumbuhan jangka panjang (steady growth). Hubungan antara tingkat investasi dan tingkat pertumbuhan yang dianggap kuat menjadi salah satu dasar bagaimana investasi kini berkembang secara global, melalui sistem foreign direct investment yang dapat mempengaruhi size stok modal keseluruhan (K) dengan Gross National Product/GNP (Y). Konteks ini kemudian diformulasikan sebagai rasio modal terhadap output (Capital Output Ratio $=$ COR). Artinya Semakin tinggi peningkatan stok modal (pertumbuhan tinggi), seharusnya semakin tinggi juga output dan pertumbuhan yang dapat dihasilkan, (Todaro dan Smith, 2004). Itulah kenapa jika dititik beratkan pada konteks eksternal, akan coba dibuktikan dalam kajian ini bagiamana foreign direct investment mempengaruhi pertumbuhan.

Kaitannya dengan aktivitas eksternal yang lain seperti konteks remitansi juga berkaitan erat dengan konsep foreign direct investment. Dapat dilihat pada Gambar 6, S-I adalah net foreign investment, sementara q merupakan nilai tukar, dan NX adalah neraca perdagangan ekspor-impor.

\section{Gambar 6. Tabungan, Investasi dan Neraca Perdagangan}

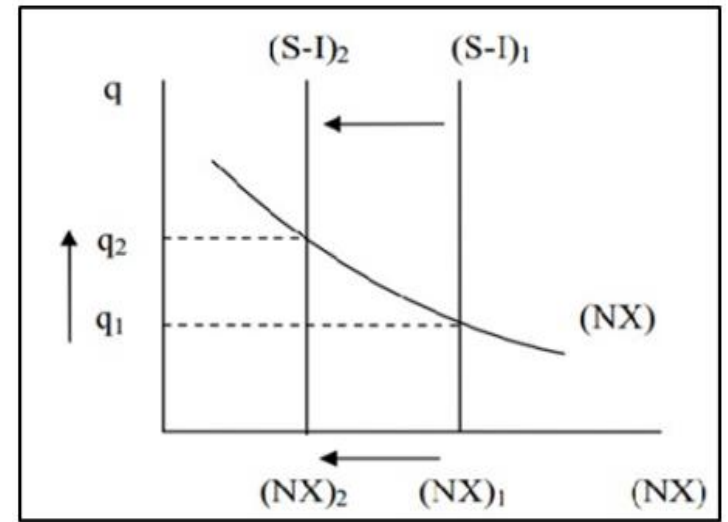

Sumber: Mankiw, 2009

Investasi yang naik dapat mendorong kurva (S-I) bergeser ke kiri, yang berarti mengurangi persedian mata uang domestik. Kemudian keseimbangan nilai tukar meningkat melalui q1 yang berubah ke q2, hal ini akan membuat mata uang domestik terapresiasi. Keadaan tersebut memicu barang-barang domestik menjadi lebih mahal dibanding barang-barang impor, sehingga ekspor turun (NX)2 menjadi menjadi (NX)1 dan impor naik.

Remitansi dalam hal ini menjadi komponen eksternal dalam bentuk capital inflow. Posisinya dapat disejajarkan dengan ekspor, foreign aid (AID), FDI dan Official Development Assitance (ODA) (Adenutsi, 2011). Peningkatan remitansi akan mendiorong meningkatnya 
permintaan mata uang domestik (apresiasi). Dalam banyak kajian apresiasi mata uang domestik akan menyebabkan penurunan ekspor dan meningkatkan impor sehingga menyebabkan defisit neraca perdagangan dan memperburuk pertumbuhan ekonomi (Tremblay, 1990; Esfahani, 1991; Zahongo, 2016).

Zahonogo (2016) menyatakan jika keterbukaan perdagangan mempunyai hubungan dengan GDP. Keterbukaan yang berorientasi pada ekspor menyebabkan pertumbuhan yang positif. Akses kredit pada sektor yang berorientasi pada ekspor menyebabkan pendapatan lebih besar, namun keterbukaan perdagangan yang berorientasi pada impor dikaitkan dengan tingkat GDP yang rendah. Akses kredit pada sektor yang berorientasi pada impor dapat mengurangi GDP. Aktar et al. (2011), menyatakan bahwa impor merupakan faktor yang dapat menurunkan pertumbuhan ekonomi. Ekspansi impor dapat mengakibatkan produksi dalam negeri kurang kompetitif, sehingga menyebabkan penurunan tingkat produktivitas dan lebih mengarah pada pelemahan pertumbuhan ekonomi. Pada kasus negara berkembang, impor dapat mempengaruhi pertumbuhan ekonomi karena adanya impor barang modal, mesin, dan input produksi menengah meningkatkan pertumbuhan ekonomi dengan adanya teknologi baru (Tremblay, 1990; Esfahani, 1991; Zahongo, 2016).

Namun hal itu berbeda dalam pandangan Tabit \& Moussir (2016) menyatakan bahwa remitansi berpengaruh negatif terhadap pertumbuhan ekonomi. Keadaan tersebut terjadi dikarenakan pada saat terjadi gejolak ekonomi di negara asal akan menyebabkan pendapatan seluruh masyarakat berkurang dan mengakibatkan beban masyarakat menjadi bertambah. Hal inilah yang mendorong para pekerja melakukan pengiriman uang lebih banyak untuk membantu dan meringankan beban keluarga di negara asal. Penerimaan remitansi yang terus meningkat dapat memberikan pengaruh yang positif terhadap pertumbuhan ekonomi. Sementara itu, Adams dan Cuecuecha (2010), menjelaskan penerimaan remitansi yang dibelanjakan rumah tangga dapat mempengaruhi pertumbuhan ekonomi. Rumah tangga yang menerima remitansi di Indonesia lebih banyak digunakan untuk belanja barang konsumsi dan makanan (memacu konsumsi agregat), apabila dibandingkan ketika rumah tangga tidak menerima pengiriman remitansi. Pengiriman remitansi akan meningkatkan permintaan uang di negara penerima, kemudian akan membuat bank meningkatkan penawaran simpanan atau tabungan (Chami et al., 2005).

Selain daripada itu, tabungan dan investasi adalah salah satu faktor penentu pertumbuhan ekonomi (Mankiw, 2009). Negara dengan tingkat tabungan yang tinggi, cenderung memiliki sumber daya yang cukup berlimpah yang dapat digunakan untuk investasi dalam barang modal. Persediaan barang modal yang cukup tinggi dapat 
menaikkan pertumbuhan ekonomi negara tersebut. Selain itu, penanaman modal asing juga memiliki peran penting dalam meningkatkan pertumbuhan ekonomi. Hal ini diperlukan untuk melengkapi sumber-sumber keuangan domestik yang rata-rata kurang mampu memberikan dana yang cukup untuk pembangunan sebuh negara. Pada konteks yang sama, hasil studi empiris yang dilakukan oleh Chenaf dan Rougier (2008) menyatakan bahwa hubungan Foreign Direct Investment (FDI) dengan pertumbuhan ekonomi sangat bergantung pada karakteristik masing-masing negara, artinya tidak selalu positif atau signifikan berhubungan langusng, bahkan ada juga yang berhubungan negatif. Dalam penelitian ini khususnya untuk negara MENA (Middle East and North Africa), FDI berpengaruh terhadap pertumbuhan ekonomi, pengaruh ini terkait efek langsung pada nilai tambah dan lapangan kerja daripada efek transfer teknologi.

Hal fundamental lainnya adalah kebutuhan daya dukung energi yang erat kaitannya dengan jumlah penduduk dan tingkat perkembangan terutama sektor industri. Kebutuhan energi dunia saat ini masih sangat bergantung pada bahan bakar fosil terutama minyak bumi, hal ini menyebabkan harga minyak dunia menjadi sangat penting dalam sektor perdagangan, mengingat persebaran cadangan minyak yang tidak merata di dunia. Harga minyak dunia terbentuk karena permintaan dan penawaran komoditas minyak dunia. Banyak negara yang masih bergantung pada negara lain dalam pemenuhan suplai minyak tersebut. Apabila penawaran minyak lebih besar dari pada permintaan minyak berarti posisi saldo cadangan devisanya positif sehingga berpengaruh pada penawaran valuta asing yang lebih tinggi dari permintaan valuta asing. Penelitian yang dilakukan oleh Shafi dan Liu (2014), menunjukkan hasil penelitian bahwa harga minyak dan nilai tukar memiliki hubungan positif terhadap kinerja pertumbuhan ekonomi di Rusia, tanda positif menunjukkan bahwa kenaikan harga minyak akan mempengaruhi secara positif terhadap produk domestik bruto dan nilai tukar juga akan meningkatkan produk domestik bruto (PDB).

\section{METODE PENELITIAN / METHODS}

Penelitian ini menggunakan teknik analisis Autoregressive-Distributed Lag (ARDL) untuk mendapatkan hubungan dan pengaruh antara variabel terikat (dependent variable) yaitu nilai pertumbuhan ekonomi Indonesia dengan variabel bebas (independent variable) yaitu impor, remitansi, foreign direct investment, dan harga minyak dunia dalam jangka pendek dan jangka panjang. Metode analisis kointegrasi ARDL diestimasi dengan bantuan 
software eviews 9. Sebelumnya analisis model dilakukan dengan menguji adanya kointegrasi untuk melihat apakah model ARDL dapat dipercaya. Jenis data yang digunakan dalam penelitian ini adalah data sekunder yang merupakan data time series bersumber dari World Bank, IMF, dan BPS periode 1980-2017. Persamaan model ARDL jangka panjang dalam penelitian ini sebagai berikut.

$$
\begin{aligned}
& G D P_{t}=\beta_{0}+\beta_{1} I M P_{t}+\beta_{1} R E M_{t}+\beta_{3} F D I_{t}+\beta_{4} W O P_{t}+E C T_{t} \\
& \text { GDP : Pertumbuhan ekonomi } \\
& \text { IMP : Impor } \\
& \text { REM : Remitansi } \\
& \text { FDI : Foreign direct Invesment/ Investasi Asing Langsung } \\
& \text { WOP : World Oil Price/Harga Minyak Dunia } \\
& \text { t : Periode waktu } \\
& \beta_{0} \ldots \beta_{4} \text { : Komponen yang digunakan untuk mengestimasi jangka panjang } \\
& \text { ECT : Error correction term }
\end{aligned}
$$

Sementara itu, persaman model ARDL jangka pendeknya sebagai berikut:

$$
\begin{aligned}
& \Delta G D P_{t}=\delta_{0}+\sum_{i=1}^{n} \lambda_{1} \Delta G D P_{t-i}+\sum_{i=1}^{n} \lambda_{2} \Delta I M P_{t-i}+\sum_{i=1}^{n} \lambda_{3} \Delta R E M_{t-i}+\sum_{i=1}^{n} \lambda_{4} \Delta F D I_{t-i}+ \\
& \sum_{i=1}^{n} \lambda_{5} \Delta W O P_{t-i}+E C T_{t-i} \\
& \delta_{0} \quad: \text { koefisien/konstanta } \\
& t-i \quad \text { : Periode kelambanan (lag) } \\
& \lambda_{1} \ldots \lambda_{5} \text { : Parameter jangka pendek }
\end{aligned}
$$

\section{HASIL DAN PEMBAHASAN / RESULT AND DISCUSSION \\ Output Estimasi}

Berdasarkan hasil uji kointegrasi bound test, menunjukkan adanya hubungan jangka panjang faktor-faktor yang mempengaruhi pertumbuhan ekonomi Indonesia.

Tabel 1. Hasil Uji Kointegrasi Bound Test

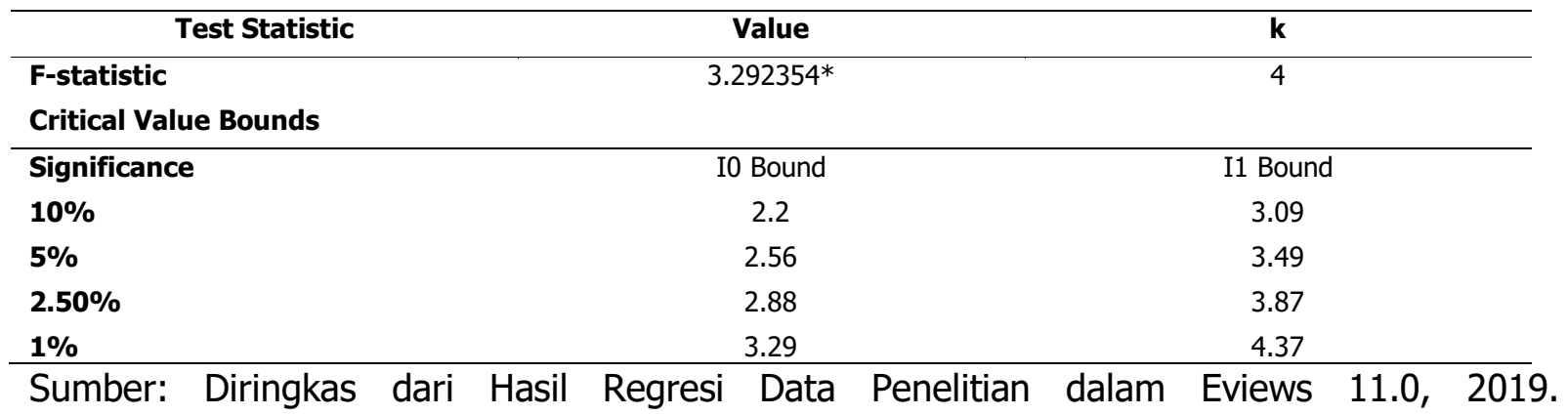


Dalam penelitian ini lag optimal dipilih berdasarkan kriteria AIC (Akaike Information Criterion). Berdasarkan kriteria AIC besarnya lag yang dipilih dalam penelitian ini adalah (1, $0,1,0,2)$ untuk masing masing variabel. Selanjutnya, berikut ini disajikan output estimasi model ARDL dalam jangka panjang dan jangka pendek, sebagai salah satu dasar bagaimana penelitian ini melihat dampak faktor eksternal terhadap pertumbuhan ekonomi Indonesia.

\section{Tabel 2. Hasil Estimasi Model ARDL}

\begin{tabular}{lcc}
\hline \multicolumn{1}{c}{ Keterangan } & Koefisien & p-value \\
\hline ECT & $-0.617246^{* * *}$ & 0.0002 \\
Jangka Panjang & & \\
C & $238.522884^{*}$ & 0.0603 \\
IMPOR & $-14.678326^{*}$ & 0.0583 \\
REMTANSI & 0.4737 & \\
FDI & $3.907806^{* *}$ & 0.0186 \\
WOP & $4.241054^{*}$ & 0,0783 \\
Jangka Pendek & & \\
D(GDP)(-1) & $0.430392^{* * *}$ & 0.0012 \\
D(IMPOR) & $-6.769574 * *$ & 0.0142 \\
D(REMTANSI) & -1.71705 & 0.1320 \\
D(FDI) & $2.223273^{* * *}$ & 0.0002 \\
D(WOP)(-1) & $-3.7047^{* *}$ & 0.0143 \\
\hline Observasi & & 36 \\
$\boldsymbol{R}$-Squared & & 0.557994 \\
Prob(F-statistic) & & 0.002073 \\
AIC & & 5.111699 \\
\hline
\end{tabular}

Sumber: Diringkas dari Hasil Regresi Data Penelitian dalam Eviews 11.0, 2019.

Keterangan: Tingkat signifikansi $* * * *$ untuk 1 persen; $* * *$ untuk $2.55, * *$ untuk 5 persen; dan * untuk 10 persen

Berdasarkan hasil output estimasi jangka panjang dan jangka pendek menggunakan model ARDL pada Tabel 2, terlihat hasil masing-masing koefisien dan tingkat signifikansi pada setiap variabel independen. ECT (Error Correction Term) memilki nilai negative 0.617246 dengan signifikanfi nilai pada $a=1 \%$. Hal tersebut menandakan bahwa semua variabel terkointegrasi atau mempunyai hubungan jangka panjang. Nilai ECT tersebut juga mencerminkan bahwa $61.7246 \%$ kesenjangan antara nilai keseimbangan jangka panjang dan nilai aktual dari variabel dependen (pertumbuhan ekonomi Indonesia), telah dikoreksi. Selain itu, dapat dimaknai bahwa kecepatan penyesuaian menuju keseimbangan jangka panjang adalah $61.7246 \%$ per tahun (data tahunan). 
Berdasarkan hasil estimasi, impor mempunyai hubungan negatif dan signifikan terhadap pertumbuhan ekonomi Indonesia jangka pendek maupun jangka panjang. Artinya peningkatan impor akan menurunkan pertumbuhan ekonomi Indonesia dalam jangka pendek jika faktor lainnya tetap. Dalam jangka panjang juga demikian, peningkatan impor akan menurunkan pertumbuhan ekonomi Indonesia jika faktor lainnya tetap. Bukti empiris ini tampak pada tren data mengenai perkembangan pertumbuhan ekonomi yang cenderung turun dan persentase jumlah impor yang semakin meningkat dibanding jumlah GDP total.

\section{Gambar 7. Pertumbuhan Ekonomi dan Persentase Jumlah Impor Yang Dibanding GDP Total}

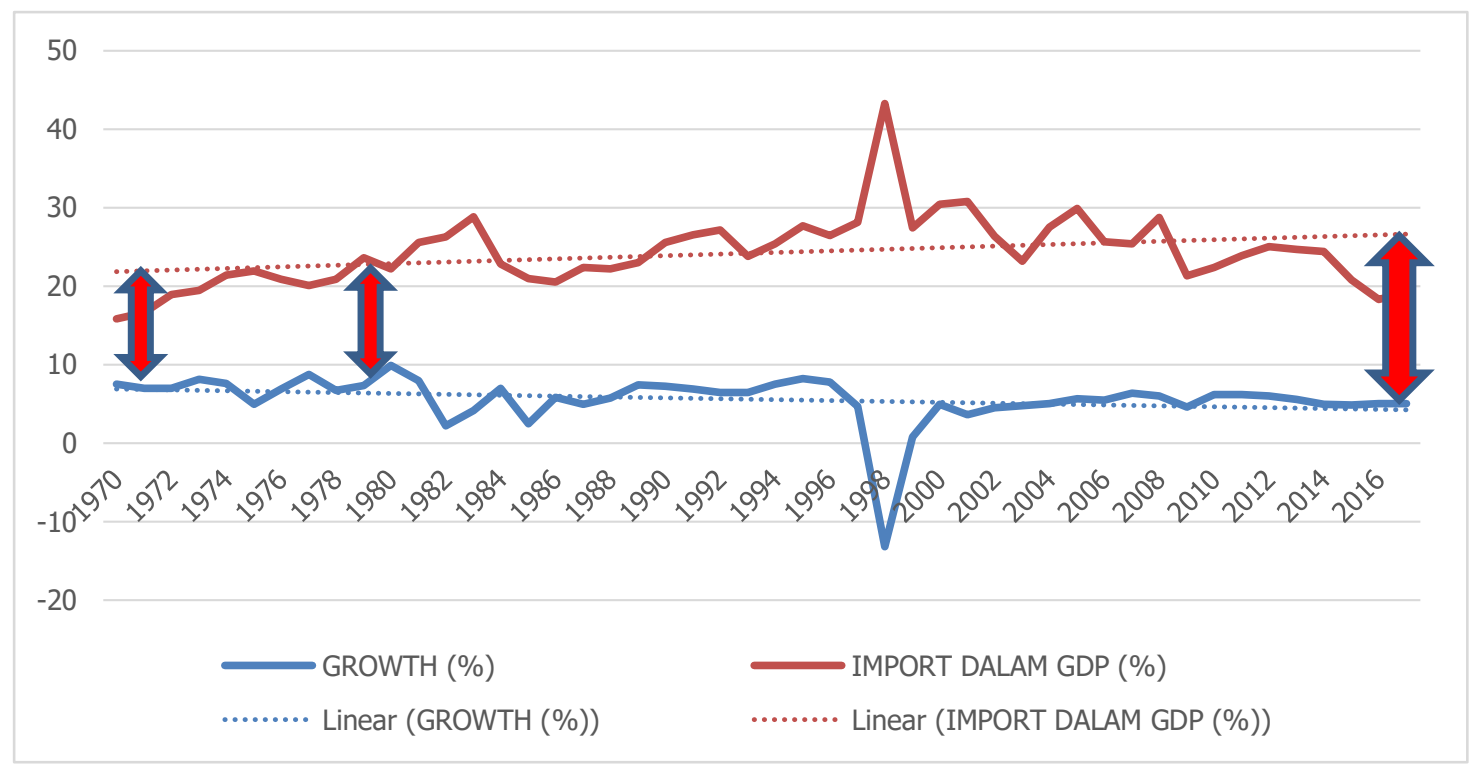

Sumber: World Bank, 2018

Hal tersebut sejalan dengan penelitian Makun (2017) yang menemukan bahwa impor memiliki pengaruh negatif dan signifikan terhadap pertumbuhan ekonomi di Kepulauan Fiji. Negara yang tergantung pada impor, khususnya impor barang modal dan mesin, serta barang habis pakai/raw materials dari negara lain, dapat memicu penurunan pertumbuhan (Tremblay, 1990; Esfahani, 1991; Zahongo, 2016). Secara konseptual impor yang sulit dikurangi (memicu defisit perdagangan) dikarenakan total produksi dalam negeri tidak mampu mencukupi kebutuhan masyarakat (Appleyard et al., 2006; Carbaugh dan Prante, 2010; Krugman et al., 2012; Carbaugh, 2015; )

Sementara itu, untuk variabel remitansi mempunyai pengaruh yang tidak signifikan terhadap pertumbuhan ekonomi Indonesia pada jangka pendek maupun jangka panjang. Hal ini terjadi dan dibuktikan dengan nilai koefisien pada variabel remitansi yang tidak signifikan pada setiap level $a=1 \%, 5 \%$, dan $10 \%$. Hasil tersebut cukup 
menarik karena berbeda dengan banyak penelitian sebelumnya. Misalnya pada pandangan remitansi berdampak pada gejolak pertumbuhan, karena dianggap dapat memicu peningkatan konsumsi keluarga, apalagi jika tidak diinvestasikan secara produktif. Apabila tidak diinvestasikan pada aset produktif selain real estate, dikhawatirkan memiliki efek multiplier Keynesian yang memicu gejolak makroekonomi dan pertumbuhan jangka pendek (Hagbe 2004). Hal ini selaras dengan temuan Ahmed (2010) yang juga menemukan efek negatif remitansi terhadap pertumbuhan ekonomi di Bangladesh.

Tabit \& Moussir (2016) juga menyatakan pendapat yang sama melalui hasil penelitiannya bahwa remitansi berpengaruh negatif terhadap pertumbuhan ekonomi. Hal ini dianggap masuk akal karena pada saat terjadi gejolak ekonomi di negara asal dapat memicu pendapatan seluruh masyarakat menjadi berkurang, sehingga beban masyarakat bertambah. Hal inilah yang mendorong para pekerja melakukan pengiriman uang lebih banyak untuk membantu dan meringankan beban keluarga di negara asal. Sementara di negara maju remitansi berdampak positif terhadap pertumbuhan, Jawaid dan Raza (2012) mengkonfrimasi melalui hasi penelitiannya bahwa hubungan antara remitansi dan pertumbuhan ekonomi di Cina dan Korea berbeda. Korea yang merepresetasikan negara lebih maju menunjukkan hasil bahwa ada hubungan jangka panjang dan pendek yang positif dan signifikan antara remitansi dan pertumbuhan ekonomi di Korea. Sedangkan di Cina remitansi dan pertumbuhan ekonomi memiliki hubungan jangka panjang yang negatif dan signifikan. Temuan penelitian ini yang menunjukkan remitansi sebagai salah satu proksi yang mencermintkan determinator eksternal tidak berdampak terhadap pertumbuhan dapat disebabkan beberapa hal, bahwa sumbangsihnya untuk memacu pertumbuhan memang kecil, uang yang dikirim tidak memacu produktivitas, manajemen portofolio keuangan skala mikro rumah tangga tidak efektid dan efisien, dan mungkin saja juga berkaitan erat dengan faktor kapabilitas penerima remitan yang tidak pro job.

Selanjutnya, variabel FDI mempunyai hubungan positif dan signifikan terhadap pertumbuhan ekonomi Indonesia jangka pendek maupun jangka panjang. Artinya peningkatan FDI dapat meningkatkan pertumbuhan ekonomi Indonesia dan jangka panjang jika faktor lainnya tetap. Hal tersebut sejalan dengan penelitian yang dilakukan oleh (Todaro \& Smith, 2006), temuannya menunjukkan bahwa FDI ternyata memiliki pengaruh signifikan dan positif pada pertumbuhan ekonomi. FDI meningkatkan pendapatan pemerintah melalui perusahaan asing yang menyumbang pajak langsung dan tidak langsung. Penerimaan pajak 
bisa meningkat seiring aliran FDI dan bagaimana pemerintah dapat menggunakannya untuk membiayai proyek-proyek pembangunannya seperti infrastruktur dan berbagai biaya modal lainnya, atau pemacu pertumbuhan yang lain. Dalam penelitian lain juga disebut bahwa FDI dapat meningkatkan produktivitas, pengetahuan (transfer keterampilan dan pelatihan tenaga kerja), dan membawa teknologi baru untuk meningkatkan pertumbuhan ekonomi negara asal seperti di negara China (Wan, 2010), Malaysia (Har et al., 2008), Jepang (Lee, 2010), Nigeria (Inekwe, 2013), India (Chakraborty dan Nunnenkamp, 2008) lingkup negaranegara Asia (Tiwari dan Mustacu, 2011), dan di berbagai negara secara umum (Lamsiraroj, 2016).

Variabel eksternal seperti harga minyak dunia juga menenujukkan hasil regresi dalam jangka pendek berpengaruh secara signifikan negatif terhadap pertumbuhan ekonomi di Indonesia. Peningkatan harga minyak dunia pada lag pertama tahun sebelumya akan menurunkan pertumbuhan ekonomi Indonesia pada jangka pendek jika faktor lainnya tetap. Kenaikan harga minyak menyebabkan penurunan output karena kenaikan harga memberikan sinyal berkurangnya ketersediaan input dasar untuk produksi. Akibatnya, laju pertumbuhan dan produktivitas menurun dalam jangka pendek. Hal ini sesuai dengan hasil penelitian Lardic dan Mignon, (2006), (2008); dan Dogrul dan Soytas, (2010), yang menyatakan bahwa guncangan harga minyak bisa menyebabkan naiknya biaya marjinal (marginal cost) produksi industri sehingga mengurangi produksi dan meningkatkan pengangguran. Kenaikan harga minyak juga menyebabkan meningkatnya inflasi. Selain itu, harga minyak mentah yang lebih tinggi akan segera diikuti oleh naiknya harga produkproduk minyak, seperti bensin dan minyak bakar yang digunakan konsumen (Cologni dan Manera, 2008), atau menjadi bagian core inflastion dalam bentuk cost push. Tidak heran, bila inflasi yang tinggi mengidentifikasikan pertumbuhan ekonomi mengalami penurunan.

Sementara itu dalam jangka panjang, harga minyak dunia juga berpengaruh secara signifikan positif. Artinya peningkatan harga minyak dunia akan meningkatkan pertumbuhan ekonomi Indonesia pada jangka panjang jika faktor lainnya tetap. Hal ini sesuai dengan penelitian yang dilakukan oleh Shafi dan Liu Hua (2014). Hasil penelitiannya menunjukkan bahwa harga minyak dan nilai tukar memiliki hubungan positif terhadap kinerja pertumbuhan ekonomi di Rusia, kenaikan harga minyak akan mempengaruhi secara positif terhadap GDP dan nilai tukar juga akan meningkatkan GDP dalam jangka panjang. 


\section{KESIMPULAN / CONCLUSION}

Berdasarkan analisis di dalam penelitian ini dapat disimpulkan bahwa variabel impor, FDI, dan harga minyak dunia berpengaruh terhadap pertumbuhan ekonomi di Indonesia dalam jangka pendek maupun jangka panjang, dengan sifat dan tanda koefisien yang tidak semuanya sama. Terdapat beberapa saran yang bisa digunakan sebagai pertimbangan untuk meningkatkan pertumbuhan ekonomi di Indonesia. Pertama, pemerintah harus dapat menentukan kebijakan yang tepat dalam rangka meningkatkan ekspor dan mengurangi impor. Salah satu upaya yang bisa dilakukan pemerintah untuk meningkatkan net ekspor adalah melakukan perbaikan atau pembangunan pada sektor migas. Misalnya penggunaan teknologi terbaru pada kilang-kilang minyak yang ada, sehingga dapat meningkatkan produktifitasnya, atau dengan melakukan eksplorasi pada lokasi-lokasi yang baru. Selama ini migas merupakan komoditas yang berperan paling besar terhadap ekspor di Indonesia.

Kedua, alokasi pengeluaran pemerintah hendaknya dimaksimalkan pada proyekproyek yang dapat mendorong timbulnya kegiatan ekonomi baru dan meningkatkan kegiatan ekonomi yang telah ada. Agar produk dalam negeri dapat bersaing pada pasar internasional, sehingga ekspor di Indonesia meningkat. Ketiga, Pemerintah harus memberikan kepastian hukum yang jelas agar investor asing dapat berinvestasi di Indonesia, sehingga perusahaan-perusahaan di Indonesia dapat berkembang dan dapat bersaing di pasar internasional sehingga, ekspor meningkat. Ketika ekspor lebih besar dari impor pertumbuhan ekonomi akan meningkat. Keempat, pemerintah perlu mengantisipasi apabila harga minyak diluar ekspektasi, ketika harga minyak terlalu tinggi mengakibatnya neraca perdagangan defisit terlalu besar. Langkah yang seharusnya dilakukan oleh pemerintah adalah mengurangi konsumsi minyak dengan cara mengkonversi energi dari fosil ke non fosil. Terakhir, pengelolaan remiten harus berorientasi pada pemunculan usaha produktif dengan potofolio manjemen keuangan rumah tangga untuk masa depan. Seyogyanya pemerintah dapat hadir dalam kondisi dan harapan ini, agar remiten memberikan sumbangan positif terhadap pertumbuhan.

\section{DAFTAR PUSTAKA / REFERENCES}

Adams, S., 2009. Can foreign direct investment (FDI) help to promote growth in Africa?. African Journal of Business Management, 3 (5), p.178.

Adams, R. H., \& Cuecuecha, A. 2010. Remittances, household expenditure and investment in Guatemala. World Development, 38(11), 1626-1641. 
Rossanto,Angga, I/ham. Dampak Faktor Eksternal Terhadap Pertumbuhan.

Ahmed MS. 2010. Migrant Workers Remittances and Economic Growth: Evidence from Bangladesh. ASA University Review. 4(1), 1-13.

Aktar, S.T.I.', Taban, S. And Aktar, İ., 2008. An empirical examination of the export-led growth hypothesis in Turkey. Journal of Yaşar University, 3(11), pp.1535-1551.

Appleyard, D., Field, A., \& Cobb, S. 2006. International Economics. 5th Edition. New York. Mc Graw

Azman-Saini, W. N. W., Baharumshah, A. Z., \& Law, S. H. 2010. Foreign direct investment, economic freedom and economic growth: International evidence. Economic Modelling, 27(5), 1079-1089.

Azoulay, P., Jones, B.F., Kim, J.D. and Miranda, J., 2020. Age and high-growth entrepreneurship. American Economic Review: Insights, 2(1), 65-82.

Barajas, A. Chami, R. Fullemkamp, C. Gapen, M. Montiel, P. 2009. Do Workers Remittances Promote Economic Growth?. International Monetary Fund, Working Paper No. 09/153, IMF

Belmimoun, A., Kerbouche, M., Adouka, L., \& Mokeddem, R. 2014. The impact of migrants'remittances on economic growth empirical study: case of algeria (19702010). European Scientific Journal, ESJ, 10 (13).

Boldeanu, F. T., \& Constantinescu, L. 2015. The main determinants affecting economic growth. Bulletin of the Transilvania University of Brasov. Economic Sciences. Series $V, 8(2), 329$.

Carbaugh, R. 2015. International Economics. 15/E. Boston. Cengange Learning.

Carbaugh, R. and Prante, T., 2010. The Temptation for Protectionism and American Trade Policy. World Economics, 11(3), 61-78.

Chakraborty, C. and Nunnenkamp, P., 2008. Economic reforms, FDI, and economic growth in India: a sector level analysis. World development, 36(7), 1192-1212.

Chami, R., Fullenkamp, C. and Jahjah, S., 2005. Are immigrant remittance flows a source of capital for development?. IMF Staff papers, 52(1), 55-81.

Chenaf, Dalila Nicet \& Rougier, Eric. 2008. FDI, Diversification and Growth: An Empirical Assessment for MENA Countries. Gretha CNRS (2008).

Chirwa, T. G., \& Odhiambo, N. M. 2016. Macroeconomic determinants of economic growth: a review of international literature. South East European Journal of Economics and Business, 11(2),33-47. 
Cologni, A and M. Manera. 2008. Oil Prices, Inflation and Interest Rates in a Structural Cointegrated VAR Model for the G-7 Countries. Energy Economics (30), 856-888.

Doğrul, H. G. and U. Soytas. 2010. Relationship between Oil Prices, Interest Rate, and Unemployment: Evidence from an Emerging Market. Energy Economics (32), 15231528.

Dornbusch, R., 2001. Fewer monies, better monies. American Economic Review, 91(2), 238242.

Esfahani, H.S., 1991. Exports, imports, and economic growth in semi-industrialized countries. Journal of Development Economics, 35 (1), 93-116.

Hagbe JB. 2004. A Theory of Workers' Remittances with an Application to Morocco. International Monetary Fund Working Paper 04/194

Handley, K., Kamal, F. and Monarch, R., 2020. Rising Import Tariffs, Falling Export Growth: When Modern Supply Chains Meet Old-Style Protectionism (No. w26611). National Bureau of Economic Research.

Har, W.M., Teo, K.L. and Yee, K.M., 2008. FDI and economic growth relationship: An empirical study on Malaysia. International Business Research, 1(2), 11-18.

Hendrix, C.S., 2019. Kicking a crude habit: diversifying away from oil and gas in the twentyfirst century. International Review of Applied Economics, 33(2), 188-208.

Inekwe, J.N., 2013. FDI, employment and economic growth in Nigeria. African Development Review, 25(4), 421-433.

Jawaid ST, Raza SA. 2012. Workers' Remittances and Economic growth in China and Korea: an Empirical Analysis. MPRA Paper no. 39003, posted 24.

Iamsiraroj, S., 2016. The foreign direct investment-economic growth nexus. International Review of Economics \& Finance, 42, 116-133.

Lardic, S., V. Mignon. 2006. The Impact of Oil Prices on GDP in European Countries: An Empirical Investigation Based on Asymmetric Cointegration. Energy Policy, 34 (18), 3910-3915.

Lee, C.G., 2010. Outward foreign direct investment and economic growth: Evidence from Japan. Global Economic Review, 39(3), 317-326.

Krugman, P., M.Obstfeld, and M.J. Melitz. 2012. International Economics: Theory and Policy 9 th Edition. United States of America: Pearson Addison-Wesley. 
Rossanto,Angga, I/ham. Dampak Faktor Eksternal Terhadap Pertumbuhan.

Makun, K. K. 2018. Imports, remittances, direct foreign investment and economic growth in Republic of the Fiji Islands: An empirical analysis using ARDL approach. Kasetsart Journal of Social Sciences, 39(3), 439-447.

Mankiw, Gregory. 2009. Principles Of Microeconomics 4th Edition. Kanada: SouthWestern Cengage Learning.

Maswana, J.C., 2020. African Economies in the Shadow of China: Effects of Bilateral Trade Structure on Economic Growth in Africa. Foreign Trade Review, 55(1), 80-92.

Meyer, D., \& Shera, A. 2017. The impact of remittances on economic growth: An econometric model. Economia, 18(2), 147-155.

Nizar, M. A. 2012. Dampak fluktuasi harga minyak dunia terhadap perekonomian Indonesia. Buletin Ilmiah Litbang Perdagangan, 6(2), 189-210.

Peters, S., 2020. Human Capital Formation and Inclusive Growth through Infrastructure. World Scientific Book Chapters, 153-181.

Shafi, K. and Liu, H., 2014. Oil prices fluctuations and its impact on Russian's economy; An exchange rate exposure. Asian Journal of Economic Modelling, 2(4), 169-177.

Sutradhar, S.R., 2020. The impact of remittances on economic growth in Bangladesh, India, Pakistan and Sri Lanka. International Journal of Economic Policy Studies, 14(1), 275295.

Tabit, S. and Moussir, C.E., 2016. Macroeconomic determinants of migrants' remittances: evidence from a panel of developing countries. International Journal of Business and Social Research, 6(7), 1-11.

Tiwari, A.K. and Mutascu, M., 2011. Economic growth and FDI in Asia: A panel-data approach. Economic analysis and policy, 41(2), 173-187.

Todaro, Michael P. dan Stephen C. Smith. 2004. Pembangunan Ekonomi di Dunia Ketiga, Edisi kedelapan. Jakarta. Erlangga

Tong, Q. and Qiu, F. 2020. Population growth and land development: Investigating the bidirectional interactions. Ecological Economics, 169, 106505.

Tremblay, R., 1990. The "export-import" effect and economic growth. North American Review of Economics and Finance, 1(2), 241-252.

Wan, X., 2010. A literature review on the relationship between foreign direct investment and economic growth. International Business Research, 3(1), p.52. 
Rossanto,Angga, I/ham. Dampak Faktor Eksternal Terhadap Pertumbuhan.

Yanikkaya, H., 2003. Trade openness and economic growth: a cross-country empirical investigation. Journal of Development economics, 72(1), 57-89.

Zahonogo, P., 2016. Trade and economic growth in developing countries: Evidence from sub-Saharan Africa. Journal of African Trade, 3 (1-2), 41-5. 